\title{
Mass Spectrometric Structure Elucidation of the Trivalent and Pentavalent Nitrogen Contaminants of Pholcodine in the Cough Relief Medical Form Tuxidrin
}

\author{
Ilia Brondz ${ }^{1,2}$ \\ ${ }^{1}$ Department of Biosciences, University of Oslo, Oslo, Norway \\ ${ }^{2} \mathrm{R} \& D$ Department of Jupiter Ltd., Ski, Norway \\ Email: ilia.brondz@gmail.com
}

Received July 5, 2013; revised August 7, 2013; accepted September 1, 2013

Copyright (c) 2013 Ilia Brondz. This is an open access article distributed under the Creative Commons Attribution License, which permits unrestricted use, distribution, and reproduction in any medium, provided the original work is properly cited.

\begin{abstract}
In the paper "Supercritical Fluid Chromatography-Mass Spectrometry (SFC-MS) and MALDI-TOF-MS of Heterocyclic Compounds with Trivalent and Pentavalent Nitrogen in Cough Relief Medical Forms Tuxi and Cosylan” [1], the presence of morphine and other degradation products of pholcodine in cough relief medical forms of Tuxi are discussed. Tuxi is recalled from the Norwegian market by Weifa pharmaceutical company, and hence it no longer presents problems to users and health authorities there; however, the medical form Tuxidrin, which contains a significant amount of pholcodine as the active pharmacological ingredient, is still marketed. In the present paper, Tuxidrin is analyzed to determine the presence of degradation products of pholcodine. The degradation of pholcodine to morphine has been discussed previously as a factor in the development of addiction to narcotics in young persons. The structures of the contaminants in Tuxidrin, such as oxides of pholcodine, are elucidated in the present paper. The toxicity and pharmacology of oxides of alkaloids have generally not been well studied, and very little is known about the toxicity and pharmacology of the degradation (oxidation) products of pholcodine: the N-oxide and the N, N'-dioxide of pholcodine. According to Brondz and Brondz [1], the N-oxide and possibly also the N, N'-dioxide are less toxic than the original alkaloids and possess greater pharmacological activity, and hence they may be a source of useful new semisynthetic drugs. The question of possible addiction to pholcodine oxides has not been studied, and the potential of these substances to provoke allergies is unclear. The recall of Tuxi from the Norwegian market is mainly based on the fact that pholcodine causes significantly increased levels of IgE antibodies in sensitized patients. Tuxidrin contains pholcodine and has the same negative effect as Tuxi, namely provoking allergies or even anaphylactic shock. From this point of view, Tuxidrin has no advantage over Tuxi. These two medical forms only differ in one respect: Tuxidrin requires a prescription (prescription duty medicine), but Tuxi does not (prescription free medicine). This aspect is also discussed in the present paper.
\end{abstract}

Keywords: High Performance Liquid Chromatography-Mass Spectrometry (HPLC-MS); Trivalent Nitrogen; Pentavalent Nitrogen; Pholcodine; Alkaloids; Addiction to Narcotics; Allergy; Tuxidrin; Morphine; Pholcodine-N-oxide,10-Hydroxy-pholcodine; IgE Antibodies

\section{Introduction}

The presence of degradation products such as morphine, pholcodine-N-oxide, and pholcodine- $\mathrm{N}, \mathrm{N}$ '-dioxide in the medical formulation Tuxi is described in [1]. The facts relating to the degradation of pholcodine to morphine had been known at the Norwegian pharmaceutical company Weifa since 1997, when analytical data for the degradation of pholcodine were presented by J. Røe in [2], and later supported in $[1,3]$. As early as 1988, Findlay strongly criticized formulations containing pholcodine [4]. To date, this situation remains unchanged. Weifa subsequently recalled Tuxi from the market, but not Tuxidrin.

The difference between Tuxi and Tuxi Forte, on the one hand, and Tuxidrin, on the other hand, is that Tuxi and Tuxi Forte do not contain ephedrine, but Tuxidrin does. Tuxidrin is a prescription duty medication, mainly because it contains ephedrine, whereas Tuxi does not require a prescription. (All forms of medication that contain even small amounts of narcotics must be sold as prescription-duty medications by law.) The necessity of including ephedrine as cough relief agent in Tuxidrin is 
questionable. Ephedrine is a sympathomimetic amine commonly used as a stimulant, appetite suppressant, concentration aid, and decongestant, and to treat hypotension associated with anesthesia. It has a similar structure to amphetamine and methamphetamine. Inclusion of ephedrine in the formulation of Tuxidrin was considered necessary for masking the harm that was observed to be caused by unrestricted, prescription-free use of Tuxi. The latter had led to an elevated number of allergy and possible asthma cases in the Norwegian population relative to the population in neighboring Sweden. In Sweden, where the dominant antitussive medication, Cosylan, was available as a prescription-duty medication, the allergic reactivity was six times lower than in Norway.

Furthermore, it is not only opiates that are under regulation. In Ireland, New Zealand, the USA, and most other countries, the $\mathrm{N}$-oxides of opium alkaloids are covered under laws and regulations for narcotics control. Pholcodine in high concentrations in medical forms is also under narcotics control laws and regulations as a morphine derivative.

As stated by Findlay in [4], pholcodine "has been formulated in many combination medications (45)-some rational and some quite irrational pharmacologically..." Pholcodine has been included in many problematic medical formulations, especially liquid mixtures with $\mathrm{pH}$ levels at which pholcodine quickly degrades. It has been shown that the opiate in the liquid medical form Cosylan does not degrade to morphine or oxidize to N-oxide [1], but in Tuxi, the opiate derivative pholcodine does. The degradation of pholcodine to morphine is strongly dependent on the $\mathrm{pH}$ of the medium [1]. The $\mathrm{pH}$ of the Tuxidrin formulation was optimized (relative to that of Tuxi) in order to retard the degradation of pholcodine to morphine; however, its $\mathrm{pH}$ was not optimized to retard the degradation of pholcodine into other oxidation products. It is therefore of interest to examine Tuxidrin for the presence of contaminants (see Figures 1 and 2).

As is mentioned in [1], and earlier in [5], N-oxides of some opium alkaloids are less toxic than original alkaloids, and often have higher specific activity than the original alkaloids alone. The toxicity of morphine-Noxide was studied, as described in [5]. The authors of [5] stated: "The intravenous and subcutaneous acute toxicities of morphine- $\mathrm{N}$-oxide (mno) in mice were respectively 3.2 and 8 times less than that of morphine. Amiphenazole or tacrine reduced the acute toxicity of mno but not that of morphine in mice. The chronic toxicity of mno was examined in mice and rats. Daily oral doses of 100 $\mathrm{mg} / \mathrm{kg}$ did not significantly affect growth or condition, or produce gross or microscopic lesions in mice treated for 3 weeks or rats treated for 3 months. No teratogenic effect of mno or of bromolysergic acid diethylamide was observed in rats".

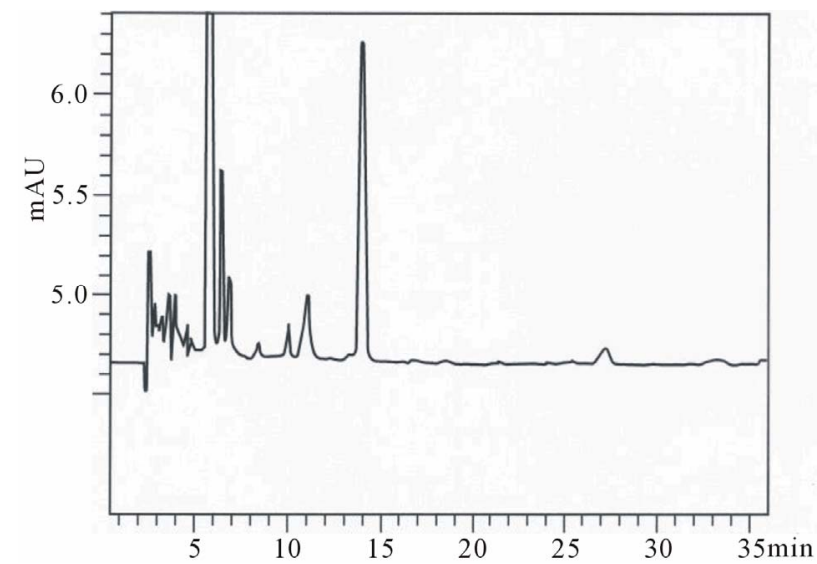

Figure 1. There is a chromatogram of Tuxidrin. Tuxidrin (hostedempende, slimløsende) mixture, produced by Weifa (Norway), was purchased from the Norwegian Medicinal Depot in Oslo, Norway.The peaks and retention times are as follows: pholcodine at $6 \mathrm{~min}, \mathrm{~N}$-oxide of pholcodine at 6.5 min, 10-hydroxy-pholcodine at $11 \mathrm{~min}$, and ephedrine at 14 min. The mass spectra of the substances corresponding to the peaks were recorded by MS with inline to HPLC. The spectra of substances related to pholcodine are given below; the mass spectra of pholcodine, $\mathrm{N}$-oxide of pholcodine, and 10-hydroxy-pholcodine are shown in Figure 4, the spectrum of ephedrine is not presented. Conditions used for HPLCMS are described in the Materials and Methods section.

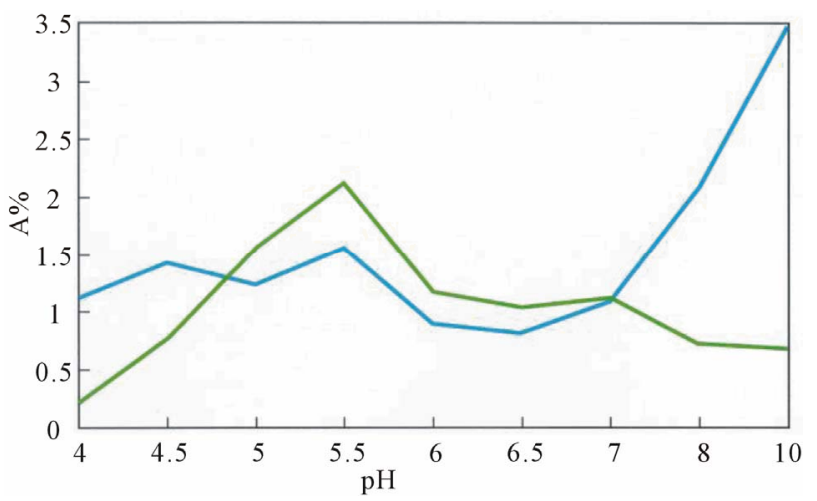

Figure 2. The percentage of oxidation products present in, calculated as a percentage of the total amount of pholcodine. The blue line is the concentration of pholcodine- $\mathrm{N}$-oxide and the green line is the concentration of 10-hydroxy- pholcodine. Temperature: $60^{\circ} \mathrm{C}$. Duration of accelerated degradation: 62 days.

The N-oxides of pholcodine mimic quaternary ammonium ions; but, they are not equivalent. However, researchers have not yet studied the tendency of quaternary ammonium ions of degradation contaminants in medical formulations containing pholcodine to provoke allergies. The major allergenic epitopes in IgE-mediated anaphylaxis to neuromuscular blocking agents (NMBAs) of degradation contaminants in medical formulations containing pholcodine were not studied.

10-hydroxy-pholcodine should possess the same al- 
lergenic potential as pholcodine. Sensitization toward a quaternary ammonium ion epitope, which NMBAs share with many common drugs and chemicals, for example, morphine, is known as one of the substances.

The presence of degradation products in Tuxidrin, which are generated during its normal shelf storage time, has practical significance, because the toxic effects of pholcodine and its degradation products are not limited to possible addiction. Expressions of toxicity include significantly increased levels of IgE antibodies in sensitized patients [6,7], and the provocation of allergies or even anaphylactic shock. In Norway, sensitivity toward NMBAs is six times higher than in neighboring Sweden. This is possibly a result of the monopolization of the cough relief drug market in Norway by Tuxi, manufactured by Weifa, as a prescription free medication, in contrast to the status of Cosylan as a prescription-duty medication in Sweden.

The generation of degradation products during shelf storage of the drug pholcodine was measured by simulation, using accelerated degradation under stress conditions (see Figures 2 and 3). The elucidation of the chemical structures of the degradation products and other contaminants was a priority in this study.

\section{Materials and Methods}

\subsection{Instrumentation and Conditions}

For HPLC analyses, an Agilent 1100 chromatograph with a diode array detector and ChemStation software (Agilent Technologies Inc., Colorado Springs, CO, USA) was used. A 50189-U-Nucleosil ${ }^{\circledR}$ HPLC column with the following parameters was used for enhanced separation: 50189-U Supelco Nucleosil ${ }^{\circledR}$ HPLC column, phase C18, length $25 \mathrm{~cm} \times$ i.d. $4.6 \mathrm{~mm}$, purchased from Sigma-Aldrich (Sigma-Aldrich, St. Louis, MO, USA). The following chromatographic conditions were used. The composition of the mobile phase was $5.0 \mathrm{~mL}$ p.a. quality triethylamine (Merck, Darmstadt, Germany) and $5.0 \mathrm{~mL}$ p.a. quality trifluoroacetic acid (Merck) added to a $1.0 \mathrm{~L}$ solution of double distilled deionized water containing $2.5 \%$ p.a. quality tetrahydrofuran (Merck) and $1.5 \%$ p.a. quality methanol (Merck). Elution was performed isocratic, using a flow rate of $1.2 \mathrm{~mL} / \mathrm{min}$. The injection volume was $20 \mu \mathrm{L}$. The HPLC system was coupled inline to a Quattro MS/MS triple quadrupole mass spectrometer (Micromass, Altrincham, UK) equipped with a pneumatically assisted electro-spray ionization source. Data acquisition and processing wereperformed using a MassLynx 4.0 SP4 data system (Waters). The effluent entered the mass spectrometer through an electro-spray capillary set at $3.0 \mathrm{kV}$ at a source block temperature of $90^{\circ} \mathrm{C}$. The desolvation gas temperature was $150^{\circ} \mathrm{C}$. Nitrogen was usedas both drying gas and nebulizing gas at flow rates of approximately 610 and $80 \mathrm{~L} / \mathrm{h}$, respectively.
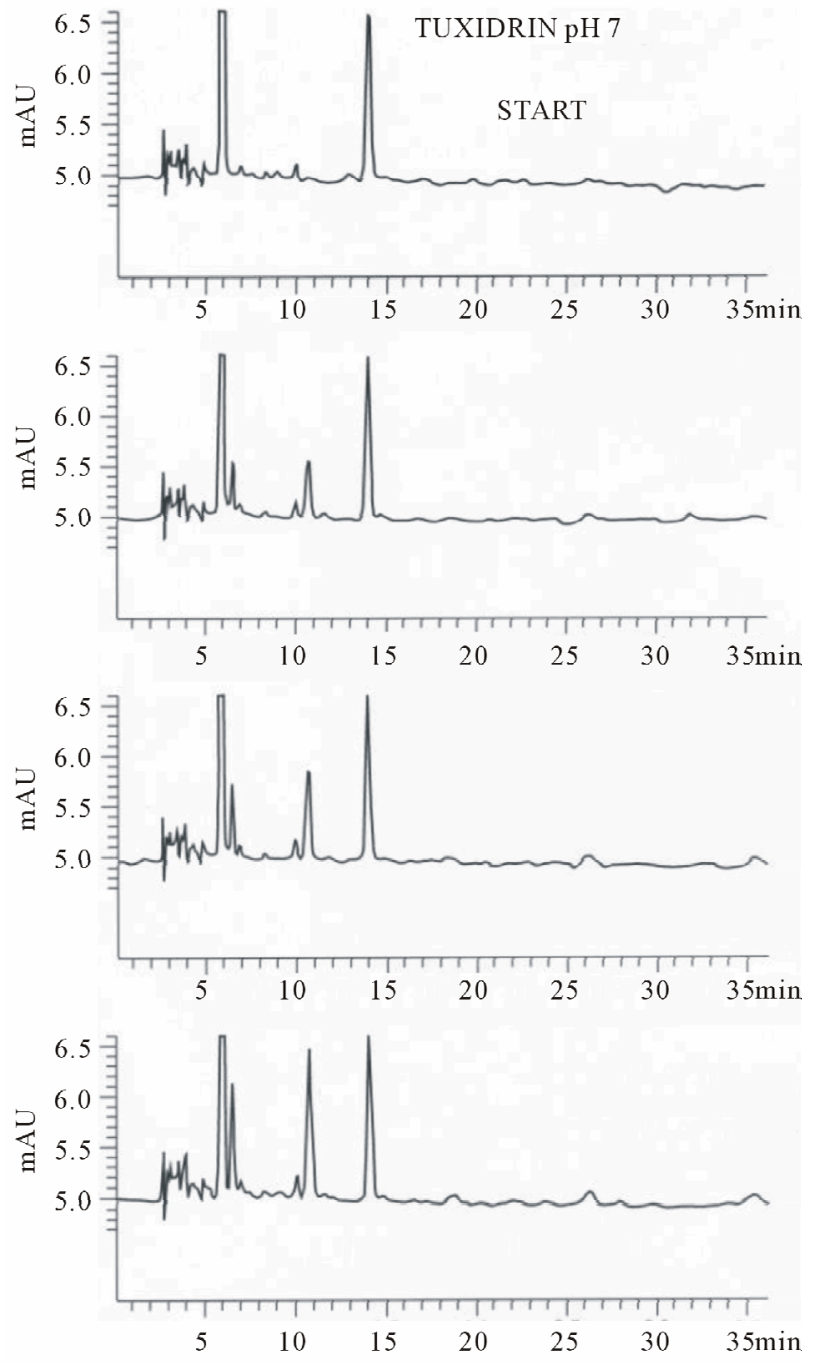

Figure 3. HPLC-MS analyses of Tuxidrin (experimental conditions described in the text). The upper chromatogram shows the Tuxidrin just off the production line, beneath is the same sample analyzed after 9, 27 and 62 days. The peaks with their retention times are as follows: pholcodine at $6 \mathrm{~min}$, pholcodine- $\mathrm{N}$-oxide at $6.5 \mathrm{~min}, 10$-hydroxy-pholcodine at $11 \mathrm{~min}$, and ephedrine at $14 \mathrm{~min}$.

The ion source parameters were optimized with respect to the positive molecular ions. The cone voltage was set at $120-210 \mathrm{~V}$. The mass spectra between $\mathrm{m} / \mathrm{z} 50$ and $\mathrm{m} / \mathrm{z}$ 600 were obtained at a scan speed of $200 \mathrm{~m} / \mathrm{z}$ units/s with a mass resolution corresponding to 1 unit at half peak height.

\subsection{Materials and Standards}

The standards used in the study are described elsewhere [1]. Tuxidrin (hostedempende, slimløsende) mixture, produced by Weifa (Norway), was purchased from the Norwegian Medicinal Depot in Oslo, Norway. It was stored for 3 years at room temperature in the original bottle un- 
til the time of analysis. The conditions for accelerated stress degradation are described elsewhere [1].

\section{Results and Discussion}

The importance of antitussive drugs is difficult to overestimate [1]; however, uncontrolled consumption of them, as in the case of Tuxi, is indefensible. The presence of narcotics and allergenic drugs in medications for consumption by children should be avoided, most especially if ingestion is a repeated act. The concern here is about not only the presence of morphine itself in the medical form, as a degradation product from the active pharmacological ingredient (API) in Tuxi and Tuxidrin, but also the presence of oxidation products and contaminants of pholcodine. The repeated consumption of opiates or derivatives ofopiates in the early stages of life has undisputable effects on the person's immune system and psychological development, and can even cause addiction to narcotics, sensitivity to allergens, asthmatic reactions, or anaphylactic shock. At the $\mathrm{pH}$ of the human stomach, pholcodine is hydrolyzed to morphine [1], as was well known by Weifa [2]. At the $\mathrm{pH}$ of the human stomach, pholcodine undergoes accelerated degradation. It is not always possible to avoid the use of cough relief medicines, but it is possible to avoid the presence of these additional, and undesirable, narcotic substances as production contaminants or degradation products in such medicines.

In this context, it was considered important to identify the degradation products of pholcodine in Tuxidrin, and to elucidate the nature of the contaminants generated during shelf storage and under different $\mathrm{pH}$ conditions. This was the aim of the present study.

Figures 1-3 show the degradation process and the accumulation of degradation products in Tuxidrin. The substances were detected at $254 \mathrm{~nm}$. The chromatography conditions were described in the previous section. The peak of the taste correcting substance is not shown in the chromatogram, as it has a long retention time in the system used here. There are four significant peaks in the chromatogram, and their spectra were recorded by MS: the first peak is pholcodine, the second and third peaks have $\mathrm{m} / \mathrm{z} 415$, and the fourth peak is ephedrine. Mass spectra are shown in Figure 4 (except the mass spectrum for ephedrine).

The elucidation of the two different contaminants with $\mathrm{m} / \mathrm{z} 415$ was based on several facts. According to Proksa [8], 10-hydroxy-morphine is a contaminant of morphine. The starting product for the synthesis of pholcodine is morphine, which may be contaminated with 10-hydroxymorphine, and one of the resulting products can be 10hydroxy-pholcodine [3] (see Figures 5(a) and (b)).

The 10-hydroxy-morphine is not the natural product of biogenesis; it is the oxidation artifact that present in an
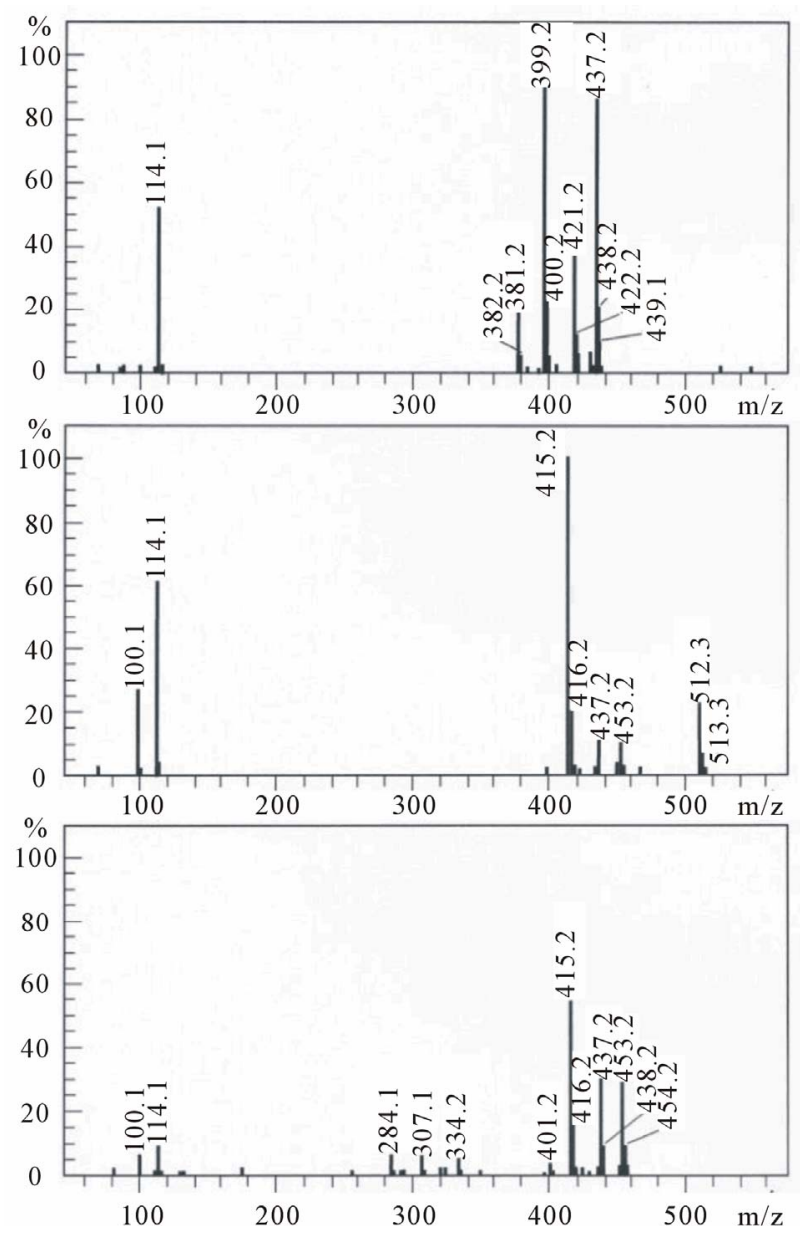

Figure 4. The mass spectra recorded for the HPLC chromatogram of Tuxidrin. The upper figure shows the massspectrum of pholcodine, the middle figure shows the mass spectrum of pholcodine-N-oxide, and the bottom figure shows the mass spectrum of a substance tentatively identified as 10-hydroxy-pholcodine. Conditions used for MS are described in the Materials and Methods section.

opium cake and/or as a result of the extraction of morphine from opium cake or poppy plant tissue. Oxygen is always present in the atmosphere and in extracting liquids; it is the cause of morphine degradation. The pholcodine in Tuxidrin can also be oxidized at positions other than the nitrogen atoms $[1,3]$. The possible appearance in the Tuxidrin of the structure Figure 5(b) within normal shelf storage times should be examined and validated. We therefore exposed Tuxidrin to thermal $\left(60^{\circ} \mathrm{C}\right), \mathrm{pH}$, and time stress. The results are shown in Figures 2-4. The concentration of both degradation substances, which are oxides, increased (Figure 3). This offers the best evidence that the substances are degradation (oxidation) products. The second substance has an identical retention time and MS spectrum to that of standard pholcodine- $\mathrm{N}$ oxide [1].

The MS spectra of the two degradation (oxidation) 


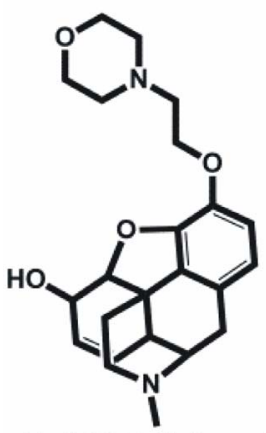

(4aS, 7R, 7a $S)$-3-methyl-9-

(2-morpholinoethoxy)-

$2,3,4,4 \mathrm{a}, 7,7 \mathrm{a}$-hexahy dro-

$1 \mathrm{H}$-4,12-methanobenzofuro

[3,2-e]isoquinolin-7-ol

\section{Structure a}

Pholcodine

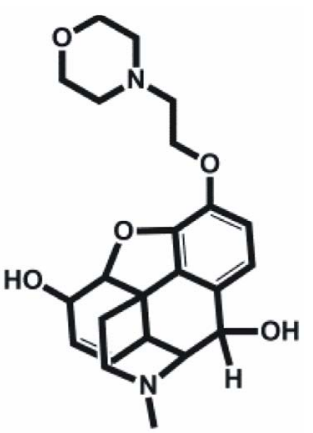

(4aS,7R,7aS)-3-methyl-9(2-morpholinoethoxy)$2,3,4,4 a, 7,7$ a-hexahydro$1 \mathrm{H}$-4,12-methanobenzofuro [3,2-e]isoquinolin-7,13-diol

$$
\begin{aligned}
& \text { Structure b } \\
& \text { 10-hydroxy } \\
& \text { Pholcodine }
\end{aligned}
$$

Figure 5. Structures: a ispholcodine, and bis10-hydroxypholcodine.

substances in chromatogram with $\mathrm{m} / \mathrm{z} 415$ do have significant differences. The spectrum of substance three shows fragmentions with $\mathrm{m} / \mathrm{z} 284$ (Figure 6(b)). A fragment ion with $\mathrm{m} / \mathrm{z} 284$ is theoretically possible for pholcodine-N-oxide (Figure 6(a)); however, under the HPLCMS experimental conditions used here, it is absent. This fragment ion with $\mathrm{m} / \mathrm{z} 284$ is also absent in the mass spectrum of pholcodine-N-oxide under the SFC-MS experimental conditions [1].

The oxidation of nitrogen at the morpholine moiety in pholcodine should yield mass spectra showing ions with $\mathrm{m} / \mathrm{z} 116$ and $\mathrm{m} / \mathrm{z} 130$ (Figures 7(a) and (b)).

The presence of ions with $\mathrm{m} / \mathrm{z} 100$ and $\mathrm{m} / \mathrm{z} 114$ in all three substances was demonstrated. There were fragment ions with $m / z 100$ and $m / z 114$ in mass spectra (see Figures 6(c) and (d)). These are fragments of the nonoxygenated morpholine moiety. In Figure 4, the ions with $\mathrm{m} / \mathrm{z} 116$ and $\mathrm{m} / \mathrm{z} 130$ were absent in the spectra of pholcodine, pholcodine-N-oxide, and 10-hydroxy-pholcodine. This is evidence that oxygenation of the pholcodine occurred at the morphine moiety.

\section{Conclusions}

1) Two degradation products in Tuxidrin with $\mathrm{m} / \mathrm{z} 415$ were recorded, and these accumulated during the shelf storage time.

2) One of these degradation products is 10-hydroxypholcodine, and the other is pholcodine-N-oxide.

3) The source of the degradation product 10-hydroxypholcodinein in Tuxidrin is pholcodine.

4) The $\mathrm{pH}$ in Tuxidrin is optimized in order to avoid the degradation of pholcodine to morphine; however, it is not adequate to prevent the degradation of pholcodine to

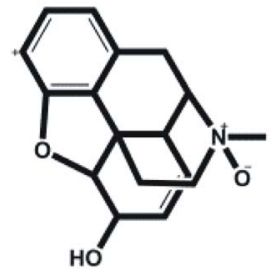

Chemical Formula: $\mathrm{C}_{17} \mathrm{H}_{18} \mathrm{NO}_{3}^{+}$ Exact Mass: 284,13 Molecular Weight:284,33 $\mathrm{m} / \mathrm{z}: 284.13$

(a)

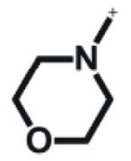

Chemical Formula: $\mathrm{C}_{5} \mathrm{H}_{10} \mathrm{NO}$

Exact Mass: 100,08 Molecular Weight: 100,14 $\mathrm{m} / \mathrm{z}: 100.08$

(c)

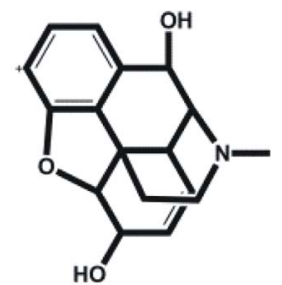

Chemical Formula: $\mathrm{C}_{17} \mathrm{H}_{18} \mathrm{NO}_{3}^{+}$ Exact Mass: 284,13 Molecular Weight:284,33 $\mathrm{m} / \mathrm{z}: 284.13$

(b)

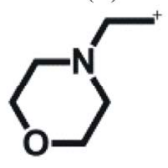

Chemical Formula: $\mathrm{C}_{6} \mathrm{H}_{12} \mathrm{NO}$

Exact Mass: 114,09 Molecular Weight: 114,17 $\mathrm{m} / \mathrm{z}: 114.09$

(d)
Figure 6. Structures of the ions with $m / z$ 284: (a) an ion theoretically derived from pholcodine- $\mathrm{N}$-oxide, and (b) an ion derived from 10-hydroxy-pholcodine and fragment ions (c) with $m / z 100$ and (d) with $m / z 114$.

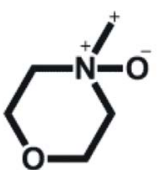

Chemical Formula: $\mathrm{C}_{5} \mathrm{H}_{10} \mathrm{NO}_{2}^{+}$ Exact Mass: 116,07

(a)

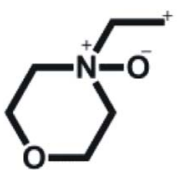

Chemical Formula: $\mathrm{C}_{6} \mathrm{H}_{12} \mathrm{NO}_{2}^{+}$ Exact Mass: 130,09

(b)
Figure 7. Structures of the ions with a $\mathrm{m} / \mathrm{z} 116$ and $\mathrm{bm} / \mathrm{z} 130$ were not recorded in the spectra of degradation products of pholcodine in Tuxidrin.

other degradation products.

5) Recalling Tuxi from the market is justified, but continued over-the-counter sale of Tuxidrin is indefensible because of the fact that the same active pharmacological ingredient is present in both products, and similar degradation substances are present in both formulations.

\section{Recommendations}

1) Allergic reactions to 10-hydroxy-pholcodine and pholcodine-N-oxide should be studied.

2) Tuxidrin should be recalled from the market, as was done in the case of Tuxi.

\section{Acknowledgements}

The author is grateful to Jupiter Ltd., Norway, for fi- 
nancial support, and to Jon Reierstad at the Technical Department of the University of Oslo, Oslo Norway, for technical assistance with the preparation of the figures.

\section{REFERENCES}

[1] I. Brondz and A. Brondz, "Supercritical Fluid Chromatography-Mass Spectrometry (SFC-MS) and MADITOF-MS of Heterocyclic Compounds with Trivalent and Pentavalent Nitrogen in Cough Relief Medical Forms Tuxi and Cosylan," American Journal of Analytical Chemistry, Vol. 3, No. 12A, 2012, pp. 870-876. doi:10.4236/ajac.2012.312A115

[2] J. Røe, "Identification of Pholcodine Degradation Products/Determination of Chemical Structures," The 13th Technical Conference, Wilmington, September 1997.

[3] O. M. Denk, G. G. Skellern and D. G. Watson, "Impurity Profiling of Pholcodine by Liquid Chromatography Electrospray Ionization Mass Spectrometry (LC-ESI-MS)," Journal of Pharmacy and Pharmacology, Vol. 54, 2002, pp. 87-98. doi:10.1211/0022357021771788

[4] J. W. Findlay, "Pholcodine," Clinical Pharmacology \&
Therapeutics, Vol. 13, No. 1, 1988, pp. 5-17. doi:10.1111/j.1365-2710.1988.tb00502.x

[5] M. R. Fennessy and H. J. Fearn, "Some Observations on the Toxicology of Morphine-N-Oxide,” Journal of Pharmacy and Pharmacology, Vol. 21, No. 10, 1969, pp. 668673. doi:10.1111/j.2042-7158.1969.tb08143.x

[6] E. Florvaag, S. G. O. Johansson, H. Öman, T. Harboe and A. Nopp, "Pholcodine Stimulates a Dramatic Increase of IgE in IgE-Sensitized Individuals. A Pilot Study,” Allergy, Vol. 61, 2006, pp. 49-55. doi:10.1111/j.1398-9995.2005.00933.x

[7] T. Harboe, S. G. O. Johansson, E. Florvaag and H. Öman, "Pholcodine Exposure Raises Serum IgE in Patients with Previous Anaphylaxis to Neuromuscular Blocking Agents," Allergy, Vol. 62, No. 12, 2007, pp. 1445-1450. doi:10.1111/j.1398-9995.2007.01554.x

[8] B. Proksa, "Separation of Morphine and Its Oxidation Products by Capillary Zone Electrophoresis," Journal of Pharmaceutical and Biomedical Analysis, Vol. 20, No. 1-2, 1999, pp. 179-183. doi:10.1016/S0731-7085(99)00015-1 